\title{
Molecular and functional analysis of SDCT2, a novel rat sodium-dependent dicarboxylate transporter
}

\author{
Xiangmei Chen, ${ }^{1}$ Hiroyasu Tsukaguchi, ${ }^{1}$ Xing-Zhen Chen, ${ }^{1}$ Urs V. Berger,${ }^{1}$ \\ and Matthias A. Hediger ${ }^{1,2}$
}

\begin{abstract}
${ }^{1}$ Membrane Biology Program and Renal Division, Department of Medicine, Brigham and Women's Hospital, and Harvard Medical School, Boston, Massachusetts 02115, USA

${ }^{2}$ Department of Biological Chemistry and Molecular Pharmacology, Harvard Medical School, Boston, Massachusetts 02115, USA
\end{abstract}

Address correspondence to: Matthias A. Hediger, Brigham and Women's Hospital, Renal Division, 77 Avenue Louis Pasteur, Boston, Massachusetts 02115, USA. Phone: (617) 525-5820; Fax: (617) 525-5830; E-mail: mhediger@rics.bwh.harvard.edu

Xiangmei Chen's present address is: General Hospital of Chinese PLA, Beijing 100853, People's Republic of China. Xiangmei Chen and Hiroyasu Tsukaguchi contributed equally to this work.

Received for publication October 1, 1998, and accepted in revised form March 1, 1999.

\begin{abstract}
Kidney proximal tubule cells take up Krebs cycle intermediates for metabolic purposes and for secretion of organic anions through dicarboxylate/organic anion exchange. Alteration in reabsorption of citrate is closely related to renal stone formation. The presence of distinct types of sodium-coupled dicarboxylate transporters has been postulated on either side of the polarized epithelial membrane in the kidney proximal tubule. Using a PCR-based approach, we isolated a novel member of the sodiumdependent dicarboxylate/sulfate transporter called SDCT2. SDCT2 is a 600 -amino acid residue protein that has $47-48 \%$ amino acid identity to SDCT 1 and NaDC-1, previously identified in kidney and intestine. Northern analysis gave a single band of $3.3 \mathrm{~kb}$ for SDCT2 in kidney, liver, and brain. In situ hybridization revealed that SDCT2 is prominently expressed in kidney proximal tubule S3 segments and in perivenous hepatocytes, consistent with the sites of high-affinity dicarboxylate transport identified based on vesicle studies. A signal was also detected in the meningeal layers of the brain. SDCT2 expressed in Xenopus oocytes mediated sodium-dependent transport of di- and tricarboxylates with substrate preference for succinate rather than citrate, but excluding monocarboxylates. SDCT2, unlike SDCT1, displayed a unique $\mathrm{pH}$ dependence for succinate transport (optimal $\mathrm{pH}$ 7.5-8.5) and showed a high affinity for dimethylsuccinate, two features characteristic of basolateral transport. These data help to interpret the mechanisms of renal citrate transport, their alteration in pathophysiological conditions, and their role in the elimination of organic anions and therapeutic drugs.
\end{abstract}

J. Clin. Invest. 103:1159-1168 (1999).

\section{Introduction}

Kidney proximal tubule cells are primarily involved in the uptake and metabolism of Krebs cycle intermediates, which include a variety of di- and tricarboxylates such as succinate, citrate, and $\alpha$-ketoglutarate (1). In the proximal tubule epithelium, the di- and tricarboxylates are taken up from both the tubular and peritubular side through sodium-coupled transport systems, thereby allowing maintenance of intracellular concentrations three- to fourfold higher than those in the plasma $(1,2)$. Transport systems of di- and tricarboxylates have been studied in intact kidney tubules (3) and vesicles from brush-border $(4,5)$ or basolateral membranes $(6,7)$, mostly using succinate and citrate as a test substrate. Numerous studies highlighted the physiological significance of the cellular uptake of Krebs cycle intermediates in proximal tubule cells $(1,2)$. First, di- and tricarboxylates are important substrates for renal metabolism. The Krebs cycle intermediates transported from tubular plasma membranes are incorporated into the intramitochondrial tricarboxylic acid cycle, thereby accounting for $10-15 \%$ of oxidative metabolism in the kidney (8). Second, intracellular accumulation of dicarboxylates confers a driving force for the counterexchange of organic anions in the basolateral membrane, which allows secretion of a variety of organic anions, including xenobiotics and drugs, from the kidney $(9,10)$. Third, reabsorption of citrate from the tubule epithelium is an important determinant of urinary citrate concentration, which is closely related to renal stone formation (11). Urinary citrate serves to chelate calcium and prevents the formation of calcium-containing stones.

Studies with intact proximal tubule and membrane vesicles suggested that at least two different sodiumdependent dicarboxylate transporters are present on either sides of the polarized proximal tubule epithelium: a low-affinity transporter with a Michaelis-Menten constant $\left(K_{\mathrm{m}}\right)$ for succinate of $400-800 \mu \mathrm{M}$ on the brushborder membrane $(4,5)$, and a high-affinity transporter with $K_{\mathrm{m}}$ for succinate of $10 \mu \mathrm{M}$ on the basolateral membrane $(6,7)$. The brush-border and basolateral transporters have been shown to share several functional features including $\mathrm{Na}^{+}$-coupled electrogenic transport and lithium sensitivity (6). Different characteristics between apical and basolateral transporters have been noted with regard to the $\mathrm{pH}$ effects on substrate transport. Citrate transport through the basolateral membrane was relatively insensitive to external $\mathrm{pH}$, whereas citrate trans- 
port through the brush-border membrane was greatly stimulated at lower $\mathrm{pH}(6)$. On the other hand, succinate uptake at the basolateral side exhibited a $\mathrm{pH}$ optimum of 7.0-7.5, whereas that on the brush-border side was relatively insensitive to $\mathrm{pH}$ changes $(6,7)$.

Over the past few years, two different mammalian dicarboxylate transporters have been identified: NaDC1 from rabbit and human $(12,13)$ and SDCT1 from rat (also known as rNaDC-1 or Ri-19) (14-16). These two isoforms are different in terms of sequence, function, and renal distribution. By expression cloning, an additional nonmammalian homologue (NaDC-2), which has $62 \%$ identity to rabbit NaDC- 1 , has been isolated from the intestine of Xenopus laevis (17). All three transporters have approximately 11 putative transmembrane domains, and they mediate electrogenic transport of most Krebs cycle intermediates in an $\mathrm{Na}^{+}$-dependent manner. These transporters also show weak (43-47\%) homology to the kidney sulfate transporter (18). Human NaDC-1 displays low affinity for citrate $\left(K_{\mathrm{m}}=7\right.$ $\mathrm{mM}$ at $\mathrm{pH}$ 7.5) (19), whereas rabbit NaDC-1 and rat SDCT1 show moderate and high affinity for citrate $\left(K_{\mathrm{m}}\right.$ $=0.9 \mathrm{mM}$ and $0.3-0.6 \mathrm{mM}$, respectively, at $\mathrm{pH} 7.5)(14$, 15). The NaDC-1 and SDCT1 transporters show a relatively wide tissue distribution that includes kidney, intestine, lung, and liver.

Immunochemical analysis revealed that both $\mathrm{NaDC}-1$ and SDCT1 are expressed in the apical membrane of kidney proximal tubule cells $(15,20)$. SDCT1 is localized exclusively in S3 proximal tubule segments. Microperfusion studies have shown that the bulk of filtered citrate or $\alpha$-ketoglutarate is reabsorbed in the convoluted S1-S2 segments of proximal tubule $(3,21)$. The exact localization within the tubule nephron of NaDC- 1 in kidney proximal tubules has not yet been reported, and whether the putative citrate transporter in S1-S2 segments, which displays low-affinity $\left(K_{\mathrm{m}}=6-7 \mathrm{mM}\right)$ and high-capacity characteristics, corresponds to NaDC-1 or a different transporter remains to be determined.

A basolateral dicarboxylate transporter cDNA has also not yet been reported. Using a PCR-based approach, we isolated a new $\mathrm{Na}^{+}$-coupled dicarboxylate transporter isoform called SDCT2, which has moderate homology to rabbit NaDC-1 and rat SDCT1 (47\% and 48\% amino acid sequence identity, respectively). When comparing the transport properties of SDCT2 with the data from apical and basolateral renal tubule studies, we found that SDCT2 corresponds to the basolateral transporter.

\section{Methods}

Cloning of SDCT2 cDNA. Total RNA was prepared from male Sprague Dawley rats by the guanidine isothiocyanate method using cesium trifluoroacetic acid (Pharmacia LKB Biotechnology Inc., Piscataway, New Jersey, USA). Poly(A) ${ }^{+}$RNA was purified by oligo-dT cellulose chromatography. Rat kidney cortex poly(A)+ RNA $(1 \mu \mathrm{g})$ was reverse-transcribed using oligo-dT primer and superscript II RNase H-reverse transcriptase (GIBCO BRL, Gaithersburg, Maryland, USA). The first-strand cDNA was subjected to PCR amplification with the degenerate oligonucleotide primers designed corresponding to a highly conserved region in the dicarboxylate transporter family (12-17): sense 5'-ATHCTNATGGCNCTNTTYTGG-3' (amino acid position 43-49 of rat SDCT1); antisense 5'-GCNGTRTTRCTDATCCACAT-3' (amino acid position 137-143 of rat SDCT1). The PCR products of the expected size ( $300 \mathrm{bp})$ were gel-purified and subcloned into the pCRII vector (Invitrogen Corp., San Diego, California, USA). One of 10 clones with homology (65\%) to SDCT1 was labeled with [32P]dCTP and used to screen a rat kidney cDNA library constructed in $\lambda$-ZAPII vector (Stratagene, La Jolla, California, USA) by using the Superscript Cloning System (GIBCO BRL). The screening was performed under the highstringency condition of washing with $0.1 \times$ SSC, $0.1 \%$ SDS at $65^{\circ} \mathrm{C}$. A positive clone containing a $3.3-\mathrm{kb}$ cDNA was isolated, and the insert was subcloned into the XbaI-BglII site of the vector pTLN2 (22) for high-level expression in Xenopus oocytes. cDNA sequence was determined on both strands and analyzed by the GCG analysis package (version 8.1; Genetic Computer Group, Madison, Wisconsin, USA).

Northern analysis. Rat multiple tissue Northern blot was purchased from CLONTECH Laboratories Inc. (Palo Alto, California, USA) and hybridized with a $\left.{ }^{32} \mathrm{P}\right] \mathrm{dCTP}-$ labeled $292 \mathrm{bp}$ of cDNA probe (nucleotide 89-380). The filter was hybridized at $42^{\circ} \mathrm{C}$ in $50 \%$ formamide and washed under high stringency ( $0.1 \times \mathrm{SSC}, 0.1 \% \mathrm{SDS}$ at $65^{\circ} \mathrm{C}$ for one hour).

In situ bybridization. Digoxigenin-labeled antisense and sense runoff transcripts were synthesized using the Genius Kit (Boehringer Mannheim Biochemicals, Indianapolis, Indiana, USA) from a PCR fragment that contained about $1.3 \mathrm{~kb}$ of SDCT2 sequence (nucleotide 456-1738) and which was flanked by SP 6 and T7 RNA polymerase initiation sites. Transcripts were alkali hydrolyzed to an average length of 200-400 bp. Hybridization was performed on cryosections $(12 \mu \mathrm{m})$ of freshly frozen tissues, based on the protocol described (23). The hybridization buffer consisted of $50 \%$ formamide, $5 \times$ SSC, $2 \%$ blocking reagent (Boehringer Mannheim Biochemicals), $0.02 \%$ SDS, $0.1 \% N$-laurylsarcosine, and probe $(\sim 200 \mathrm{ng} / \mathrm{ml})$. Sections were immersed in slide mailers and hybridized at $70^{\circ} \mathrm{C}$ for $18 \mathrm{~h}$. Sections were then washed three times in $2 \times$ $\mathrm{SSC}$ and twice for $30 \mathrm{~min}$ in $0.1 \times \mathrm{SSC}$ at $70^{\circ} \mathrm{C}$. The hybridized digoxigenin-labeled probes were viewed using anti-digoxigenin Fab fragments (Boehringer Mannheim Biochemicals) and BCIP-NBT substrate. The sections were developed in substrate solution for $16 \mathrm{~h}$, rinsed in $10 \mathrm{mM}$ Tris and $1 \mathrm{mM}$ EDTA ( $\mathrm{pH}$ 8.0), and coverslipped with VECTASHIELD (Vector Laboratories, Burlingame, California, USA).

In vitro transcription and functional characterization. SDCT2 cRNA was synthesized in vitro from the MluI-linearized SDCT2 cDNA using SP6 RNA polymerase. SDCT1 cRNA was prepared from SDCT1 cDNA (GenBank AF058714) as described previously (14). Stage V and VI oocytes from Xenopus laevis were dissected and injected with water or SDCT2 cRNA $(25 \mathrm{ng})$. After three to four days' incubation at $18^{\circ} \mathrm{C}$, uptake of $\left[{ }^{14} \mathrm{C}\right]$ succinate or citrate was measured in uptake buffer containing $100 \mathrm{mM} \mathrm{NaCl}$ (sodium buffer) or choline $\mathrm{Cl}$ (choline buffer), $2 \mathrm{mM} \mathrm{KCl}, 1 \mathrm{mM}$ $\mathrm{CaCl}_{2}, 1 \mathrm{mM} \mathrm{MgCl}$, and $10 \mathrm{mM}$ HEPES-Tris (pH 7.5). For $\mathrm{pH}$ sensitivity experiments, solutions were buffered to a range of $\mathrm{pH}$ values between 5.5 and 8.0 using $0-5 \mathrm{mM}$ MES, $0-5 \mathrm{mM}$ HEPES, and 0-5 mM Tris base. For the transport assays, groups of seven to 10 oocytes were washed briefly in uptake solution and then incubated in $0.5 \mathrm{ml}$ of the appropriate uptake solution, as described in the corresponding figure legends. After the indicated period, the uptakes were stopped with five 3-ml washes of ice-cold uptake solution. Individual oocytes were transferred to scintillation vials and dissolved in $0.2 \mathrm{ml}$ of $10 \%$ SDS, and the radioactivity was assayed by scintillation counting.

Electrophysiology. The two-microelectrode voltage-clamp technique was used in conjunction with a commercial amplifier (Clampator CA-1B; Dagan Corp., Minneapolis, Minnesota, USA) (14). The oocytes were superfused at approximately 1.5 $\mathrm{ml} / \mathrm{min}$ with the same buffer as uptake assay. In experiments 
involving voltage jumps, currents and membrane potentials were digitized at 150 seconds per sample with Bessel filtering at $10 \mathrm{kHz}$. When recording currents at a holding potential or endogenous membrane potentials, digitization at $2 \mathrm{~Hz}$ and filtering at $20 \mathrm{~Hz}$ were used. After microelectrode implements, the membrane potential was allowed to stabilize during five minutes. The oocytes were clamped to the holding potential $\left(\mathrm{V}_{\mathrm{h}}\right)$ of $-50 \mathrm{mV}$. In voltage-jump experiments, $100-\mathrm{ms}$ voltage pulses between -160 and $+60 \mathrm{mV}$, in increments of $+20 \mathrm{mV}$, were applied. Steady-state currents were obtained as the average values between 80 and $95 \mathrm{~ms}$ after initiation of voltage pulses. Substrate-evoked currents were evaluated as the difference between currents recorded before and after substrate addition. Experimental results were expressed in the form of mean \pm SE $(n)$, where $n$ indicates the number of oocytes obtained from at least two different donors. The curve-fitting procedures was performed using the Hill equation of $I=I_{\max }{ }^{*}[\mathrm{~S}]^{\mathrm{nH}} /\left\{\left(K_{m}\right)^{\mathrm{nH}}+\right.$ $\left.[\mathrm{S}]^{\mathrm{nH}}\right\}$, where $I$ is the current, $I_{\max }$ is the maximum current at saturating substrate concentration, $K_{m}$ is the substrate concentration at half-maximal current, and $\mathrm{n}_{\mathrm{H}}$ is the Hill coefficient.

\section{Results}

Isolation of SDCT2 cDNA. A 292-bp PCR fragment generated by PCR amplification using a degenerate oligonucleotide primer (see Methods) was used as a probe to screen a rat kidney cortex cDNA library. Highstringency hybridization screening yielded a 3,338-bp cDNA, designated SDCT2, which predicts an open reading frame of 1,800 nucleotides. The open reading frame is flanked by 95 nucleotides of $5^{\prime}$-untranslated sequence and 1,443 nucleotides of $3^{\prime}$-untranslated sequence. The cDNA has a poly $(\mathrm{A})^{+}$tail, which is preceded by a polyadenylation site (AATAAA). SDCT2 encodes a 600 -amino acid residue peptide with a predicted molecular mass of $66 \mathrm{kDa}$ (Figure 1a).

Hydropathy analysis of SDCT2 predicts at least 11 membrane-spanning domains, similar to the findings of Pajor and Sun (20). Elucidation of the membrane topology of sodium-dependent dicarboxylate transporters, however, awaits further studies because predictions based on hydropathy analysis are unclear. SDCT2 contains three consensus sites for phosphorylation by protein kinase $\mathrm{C}$ and two consensus sequences for $\mathrm{N}$-linked glycosylation at the $\mathrm{COOH}$-terminal tail (Figure 1c). A search of the genebank database indicated that SDCT2 shares moderate identity with rat SDCT1 (48\%) (14-16), rabbit NaDC-1 (47\%) (12), human NaDC-1 (47\%) (13), Xenopus laevis intestinal NaDC-2 (48\%) (17), and rat sodium-coupled sulfate transporter NaSi-1 (40\%) (18). There is no significant homology to other known mammalian sodium-coupled transporters.

Tissue distribution of SDCT2 $m R N A$. High-stringency Northern analysis (Figure 2) revealed a single transcript of $3.3 \mathrm{~kb}$, which is strongly expressed in kidney and, to a lesser degree, in liver and brain. No hybridization signals were observed in mRNA from heart, spleen, lung, skeletal muscle, and testis (Figure 2) and intestine (data not shown). This contrasts the pattern of expression of SDCT1, which is restricted to kidney and intestine $(14,15)$. In situ hybridization was used to determine the exact distribution of SDCT2 mRNA. In kidney, the highest expression was found in the early parts of S3 proximal tubules (i.e., junction to S2 segments), and the signals were gradually attenuated toward the late parts of S3 (Figure 3a). In liver, SDCT2 mRNA was found in hepatocytes, apparently only those surrounding the central vein (Figure $3 \mathrm{~b}$ ). In brain, SDCT2 mRNA was detected in meningeal layers, including cells of the pia mater and arachnoid (Figure 3c). No labeling was observed in choroid plexus and blood capillaries.

Functional characteristics of SDCT2. Transport characteristics of SDCT2 were determined in oocytes expressing SDCT2. Radiotracer uptake at $\mathrm{pH} 7.5$ showed that SDCT2 induced a 150 -fold stimulation for succinate transport (138 $\pm 7 \mathrm{pmol} /$ oocytes $/ 10 \mathrm{~min}$ ) and 30-fold for citrate transport (42 $\pm 3 \mathrm{pmol} /$ oocytes $/ 10 \mathrm{~min}$ ), compared with water-injected control oocytes $(0.9 \pm 0.2$ and $1.3 \pm 0.4 \mathrm{pmol} /$ oocytes $/ 10 \mathrm{~min}$, respectively) (Figure $4 \mathrm{a}$ ). Substitution of sodium with choline in uptake buffer abolished transports of succinate and citrate, indicating their dependency on extracellular sodium. Experiments under voltage-clamp conditions $\left(\mathrm{V}_{\mathrm{h}}=-50 \mathrm{mV}\right.$ ) (Figure $4 \mathrm{~b})$ indicated that SDCT2-mediated transport is electrogenic and that substrate-elicited inward currents are dose dependent and saturable (Figure 4, c and d). The apparent affinity constant $\left(K_{\mathrm{m}}\right)$ for succinate $\left(K_{\mathrm{m}}^{\text {succ }}\right)$ is 15 $\pm 1.3 \mu \mathrm{M}(n=5)$, whereas that for citrate $\left(K_{\mathrm{m}}^{\mathrm{cit}}\right)$ is $220 \pm 10$ $\mu \mathrm{M}(n=5)$. The transport kinetics are almost comparable to those of rat SCDT1, where $K_{\mathrm{m}}^{\text {succ }}$ is $24 \pm 2 \mu \mathrm{M}$ and $K_{\mathrm{m}}^{\mathrm{cit}}$ is $640 \pm 10 \mu \mathrm{M}$ (the same experimental conditions were used) (14). However, affinity for succinate of SDCT1 and SDCT2 is one order of magnitude higher than that of rabbit NaDC-1 $\left(K_{\mathrm{m}}^{\text {succ }}=400 \mu \mathrm{M}\right)(12)$. The data indicate that SDCT1 and SDCT2 share a similar substrate preference (both have a 15- to 30-fold higher affinity for succinate over citrate) and represent a highaffinity dicarboxylate transporter.

To explore further the substrate selectivity, we applied a variety of potential substrates to SDCT2expressing oocytes under voltage-clamp conditions (Figure 5a). Dicarboxylates, including malate, $\alpha$-ketoglutarate, oxaloacetate, and fumarate, evoked large currents equivalent to those induced by succinate. In contrast, tricarboxylate citrate generated relatively small currents, only $20-30 \%$ of succinate-mediated currents. Notably, L-aspartate evoked currents $80 \%$ of those induced by succinate, whereas D-aspartate and D- and L-glutamate gave currents $20-40 \%$ of the succinate currents. No transport-mediated currents were observed for lactate and pyruvate. Taken together, these data indicate that SDCT2, similar to SDCT1, mediates electrogenic, sodium-coupled transport of a variety of Krebs cycle intermediates, as well as acidic amino acids, but excluding monocarboxylates $(14,15)$.

To determine whether SDCT2 exhibits the characteristics previously reported for the renal basolateral dicarboxylate transporter, we used 2,3-dimethylsuccinate and methylsuccinate as test compounds $(24,25)$. Transport studies of luminal and contraluminal dicarboxylate uptake in rat kidney proximal tubules showed that 2,3-dimethylsuccinate is specifically recognized by the basolateral transport system. In contrast, methylsuccinate was recognized by both basolateral and apical transport systems (24). Voltage-clamp experiments 
WLAALAKKVWSARRLLVLLLVPLALI PILFALP PKBGRCLYVILLMAVYWCTEALPLSVTALLFI ILFPFMGILFGSKVCPQYELDTNFLFLSGLIMA . MATCWPALWAYREYLIVLCLPI FLLPLPLIVQTKEAYCAYSIILMALLWCTBALPLAVTALLPIVLFPLMGTMDASEVCIBYFKDTNILFVGGLMVA ...MATCWQGLWAYRMYLLVFLLPISLLPLPILVPRKEAYCAYATTLMALFWCTDALPLAVTALLELCLFPMMGIMEASEVGLEYLKDTNVLEIGGLLLA - MATCWQALWAYRSYLIVFFV ILLLPLPILVPSKEAYCAYAT TLMALFWCTEALPLAVTAL FELILFPMMGIVDASEVAVEYLKDSNLLE'FGGLLVA

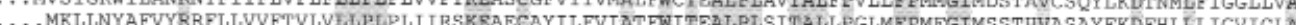

101

3

4

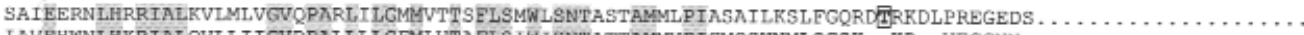

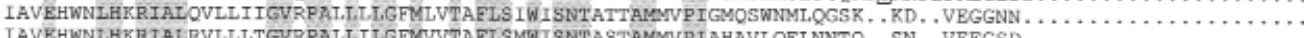

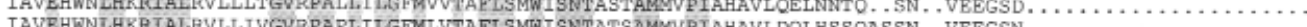

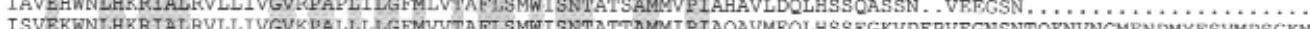

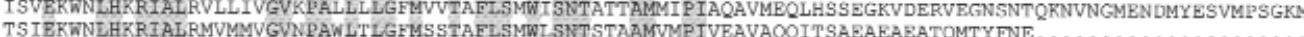
TS IEKWNLHKRIALRMVMMVGVNPAWLTLGFMSSTAFLSMWLSNTSTAAMVMPIVEAVAQQITSAEAEAEATOMTYFNE $\ldots \ldots \ldots \ldots \ldots \ldots \ldots$

..TAAVRGNGLRTVP..... TEMQFLASSEGGHAEDVEAPLEL.PDDSKBEEHRRN $\ldots .$. IWKGFLISIPYSASTGGTATLTGTAPNLILL

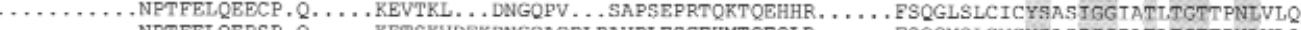
$\ldots \ldots \ldots \ldots$ NPTFELQEPSP. $Q \ldots \ldots$ KETSKVDEKDNGQAOPLPAVPLESGEHMTQEQLR . . . . . F F QGMSLCVCYSASTGGTATLTGTTPNLVL

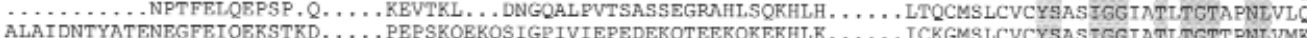
-

301

6400

GQLKSFFPQ . .CDVVVFGSWFI FAFPLMLLFLLVGWLWISFLYGGMSWR. GWRKKNSKLODVAEDKAKAVIQEEFQNLGPI KFA. EOAVFILFCLFAILI.

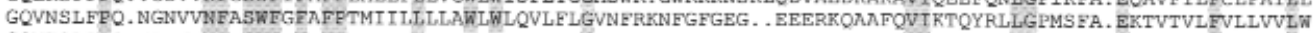

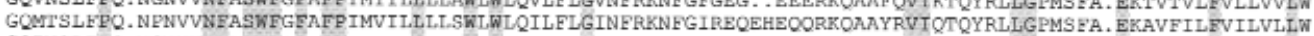

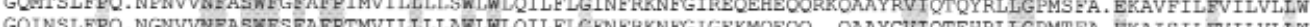
GQNSLP.NGN GQWDELFFE. NNAINEASWFGEAFPTMLVL.LALSWLWLQFIYLGVNFKKNFGCGGNAEQKEKEKRAFRVISGEHKKLGSMTFA. EISVLVLFILLVLIW EHFNTRYPD . . CRCLNEGSWFLFSFPVAVILILLSWIWLQWLFLGFNFKEMFKCGKTK. .TLKEKACAEVIKQEYEKLGPMRY. QEIVTLVI IIVMALLW

401 7

8 500

YSDCT2 FSRDPRFIPCWASLF . . . A.APGEVSDAVTGVAIVTILFFFPSOKPSLKW . . . . . WFDFKAPNSETEPLLSWKKAOETVPWNTILLLGGGEAMAKGC

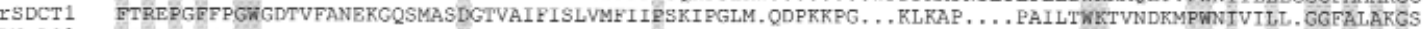
RNaDC1 FTREPGFFHGKGNLVSDASGRVMVSDGSASILIGVFLFMVESKI PGLT.QDPDNPG . . RLKAP.... PALLNWKLVNKKMPWNIVLIILG6GYALARGS hNaDC1 FTREPGEFLGKGNLAFPNAKGESMVSDGTVAT FTGI TMFI IPSKFPGLT.QDPENPG . . KL KAP . . . LGLLDWKIVNQKMPWNIVLLLGGGYALAKGS XNaDC2 FTREPGFMPGWATISF. NKGGKEMVTDATVAIFVSLMMFFFPSELPSFKYQDTDKPGMKFKLRVP. ... PALLDNKTVNEKMPWNIVIILGGGFALAKGS

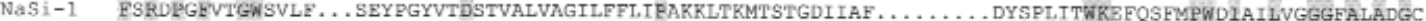

501 9 10

600

BESGLSAW IGGQLHPLEHVPPPLLAVLLITVVIAFFTEFRSNTATI I FLBVLAELAIRLHVHPLYLMIPGTVSCSYAFMLPVSTPINSIAFETGHLLVKD BQ3GLSEWLGDKLTPLQHIPPSATAVILCLLIAI FTECTSNVATTTLFLPILASMAQAICLHPLYVMLECTLAASLAFMLPVAT EPNAMVES FGGLKVSD BESGLSQWLGNKLMPLQHVPPPATVEI ICLLVATFTECTSNAATTTLLLPILASMAQAICLHPLYVMLPCTLASSLAFMLPVATPRNAIVFSFGGLRVSD BR3GLSEWLGNKLTPLQSVPAPAIAI ILSLLVATFTECTSNVATTTIFLPILASMAQAICLHPLYVML PCTLATSLAFMLPVATPPNAIVESFGDLKVLD BESGLSLWLGBKLTPLQSIPPAAIALILCLLVATETECTSNVATTTLFLPILASMAKAIQLNPLYIMLCTLSASIAFMLPVATPPNAIVES FGDLKVLD

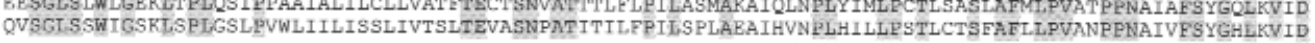

601 11

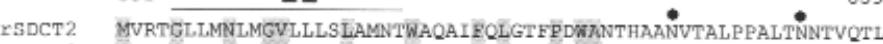
YSDCT1 MARAGFLLNT TGVLAITLSINSWSIPIEKLDTFPSWAISN,TSQCLLNPSNSTVPGGL. RNADC1 MARAGIMLNI I GVLVIMLAINSWGVPMROLHTEPSNAHSNSTTHCLAS.. PPTAPSP.. hNADC1 MARAGFLLNI IGVLIIALATNSWGI PLFSLHSFPSWAQSNTTAOCLPSL.ANTTTPSP. .

xNaDC2 MAKAGLLLNILGVLTITLAINSWGFYMFNLGTFPSWA. . NATGQH . . . . . . . .

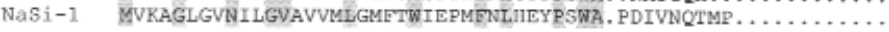

b

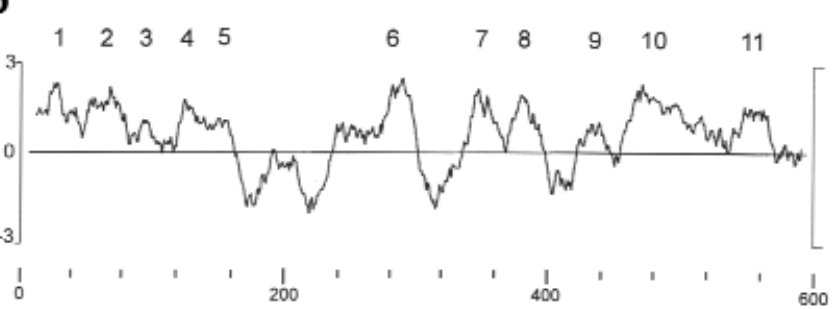

Figure 1

Predicted amino acid sequence of the rat SDCT2. (a) Amino acid alignment of members of the SDCT family. Sequences of rat SDCT2 (rSDCT2; GenBank AF080451), rat SDCT1 (rSDCT1; GenBank AF058714), rabbit NaDC-1 (RNaDC-1; GenBank Q28615), human NaDC-1 (hNaDC-1; GenBank Q13183), Xenopus laevis NaDC-2 (xNaDC-2; GenBank U87318), and rat sodium-dependent sulfate transporter NaSi-1 (GenBank Q07782) are aligned by C

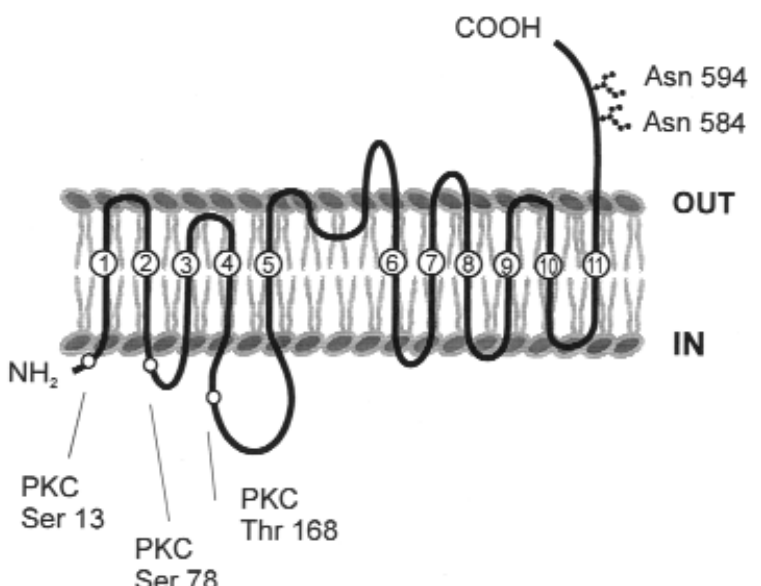
PILEUP (GCG analysis program). Identical residues are indicated by shading. The putative transmembrane domains are underlined and indicated by numbers. The consensus sequences for $N$-linked glycosylation (Asn 584, Asn 594) (asterisks) and potential protein kinase $C$ phosphorylation sites (Ser 13 , Ser 78, Thr 168) (boxes) are shown. (b) Hydropathy analysis of SDCT2. The hydropathy profile was analyzed by the Kyte-Doolittle algorithm with a window of 21 residues. Putative membrane-spanning domains are shown by numbers. (c) Hypothetical membrane topology model of SDCT2. Membranespanning domains are predicted based on the hydropathy profiles. The numbering of the putative 11 transmembrane domains corresponds to $\mathbf{b}$. 
(Figure 5b) showed that SDCT2 transports 2,3dimethylsuccinate and methylsuccinate with high affinities $\left(K_{\mathrm{m}}=27.2 \pm 2.2\right.$ and $8.8 \pm 1.1 \mu \mathrm{M}$, respectively) and that these substrates evoke $60-100 \%$ of the succinate-evoked currents. In contrast, SDCT1 showed low affinity for 2,3-dimethylsuccinate $(272 \pm 3 \mu \mathrm{M})$ and relatively high affinity for methylsuccinate $(96 \pm 13 \mu \mathrm{M})$; 2,3-dimethylsuccinate evoked only $17 \%$ of the succinate-evoked current. These transport characteristics of SDCT2 are consistent with basolateral transport.

To determine the effects of $\mathrm{pH}$ on transport of succinate and citrate, we performed radiotracer uptake studies (Figure 6, a and b) and electrophysiological experiments (Figure 6, $\mathrm{c}$ and $\mathrm{d}$ ) in the $\mathrm{pH}$ range 5.5-8.5. Tracer studies showed that succinate uptake at $\mathrm{pH} 5.5$ is sevenfold lower than at $\mathrm{pH} 7.5$ (19.8 \pm 3.2 vs. $147 \pm 14 \mathrm{pmol} /$ oocytes $/ 10 \mathrm{~min}$ ) (Figure 6a), consistent with the electrophysiological data showing that succinate evoked seven- to eightfold smaller currents at $\mathrm{pH} 5.5$ compared with $\mathrm{pH} 7.5$ (Figure 6c). The remarkable $\mathrm{pH}$ dependence of succinate transport by SDCT2 contrasts the $\mathrm{pH}$ independence of succinate transport by NaDC-1 and SDCT1 (12-14). Notably, citrate transport exhibited a $\mathrm{pH}$ sensitivity opposite to that of succinate. Citrate uptake is threefold higher at pH 5.5 compared with pH 7.5 (64.5 \pm 4.1 vs. $21.6 \pm 0.3$ pmol/oocytes/10 min) (Figure 6b), and citrate-induced currents were augmented at lower $\mathrm{pH}$ (Figure 6d). The stimulation of citrate transport at lower $\mathrm{pH}$ is analogous to NaDC-1 and SDCT1 (12-14) and is related to the increased population of the divalent form of citrate below its $\mathrm{pK}_{\mathrm{a} 3}$ of 6.4 (6).

The cation-substrate interaction was examined by measuring substrate-dependent currents under various concentrations of sodium $(0-100 \mathrm{mM})$. Determination of current-voltage relationship under different extracellular sodium concentrations indicated that transport depends on both membrane potentials and external sodium concentration (Figure 7a). In the presence of sodium, the succinate-evoked currents displayed a curvilinear dependence on membrane potential, roughly liner between -80 and $+10 \mathrm{mV}$. When external sodium concentration was increased at a given membrane potential $\left(\mathrm{V}_{\mathrm{h}}\right)$, succinate-induced currents showed a sigmoidal dependence on sodium concentration (Figure 7b). At $\mathrm{V}_{\mathrm{h}}=-50 \mathrm{mV}$, SDCT2 displayed an apparent sodium affinity $\left(\mathrm{K}_{\mathrm{m}}^{\mathrm{Na}}\right)$ of $19.6 \pm 1.2$ $\mathrm{mM}$, a Hill coefficient $\left(\mathrm{n}_{\mathrm{H}}\right)$ of $2.07 \pm 0.15$, and a maximal current $(\mathrm{I} \underset{\max }{\mathrm{Na}}$ ) of $-85.7 \pm 10.8 \mathrm{nA}$. The apparent affinity constant of SDCT2 for sodium is similar to that reported for SDCT1 (K $\mathrm{ma} 17.6 \pm 0.7 \mathrm{mM})(14)$. The Hill coefficient of 2.07 indicates that at least two sodium ions are coupled to one succinate molecule.

We next tested the cation specificity by replacing sodium with lithium in the superfusion buffer. When superfused in $100 \mathrm{mM} \mathrm{LiCl}$ solution, SDCT2-expressing oocytes did not show any substrate-dependent currents, indicating that lithium does not drive substrate transport (data not shown). To assess further the specificity for coupling cations, we measured succinate-evoked currents at the two concentrations of $\mathrm{Na}^{+}$solutions $(20$ and $100 \mathrm{mM}$ ) in the presence of
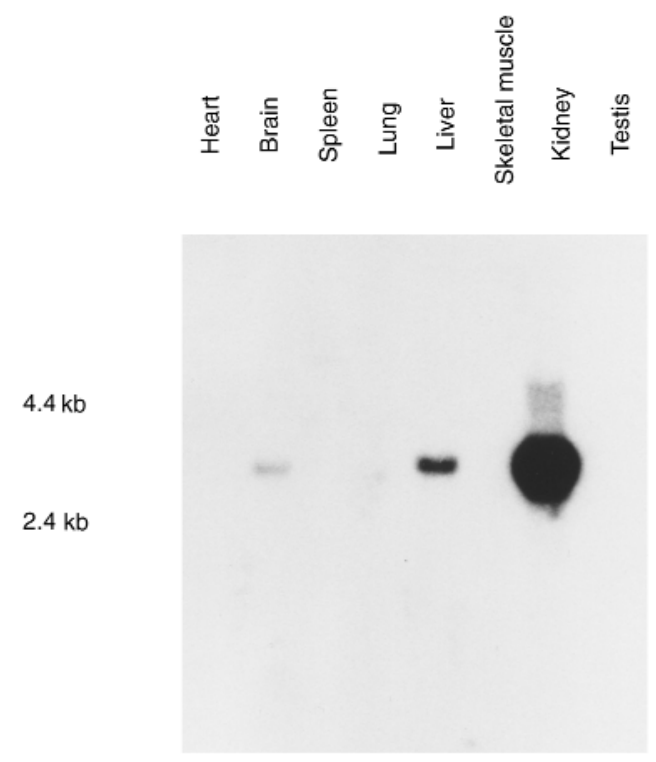

Figure 2

Northern blot analysis of SDCT2 mRNA in rat tissues. Northern blot with poly $(A)^{+}$RNA ( $2 \mu \mathrm{g}$ ) from the rat tissues was hybridized with a SDCT2 cDNA probe under high-stringency conditions. The positions of size standards (measured in $\mathrm{kb}$ ) are shown at left.

LiCl (3 mM) (Figure 4b and 7c). Addition of lithium significantly reduced sodium-coupled, succinateevoked currents down to $61 \pm 3 \%(100 \mathrm{mM})$ and $38 \pm$ $6 \%(20 \mathrm{mM})$, compared with those obtained in the absence of lithium at the same sodium concentration. The sensitivity to lithium inhibition of SDCT2 is similar to that reported for rat SDCT1 and rabbit NaDC$1\left(K_{i}^{\mathrm{Na}}\right.$ for lithium $\left.=2 \mathrm{mM}\right)(14,18)$ and much higher than that of human NaDC-1 $\left(K_{i}^{\mathrm{Na}}\right.$ for lithium $=20$ $\mathrm{mM}$ ) (18). Thus, lithium is able to occupy the cation binding site with high affinity but does not induce substrate translocation.

\section{Discussion}

We report the molecular cloning and functional characterization of a novel renal sodium-coupled dicarboxylate transporter, SDCT2. Analysis of the sequence and predicted secondary structure reveals that SDCT2 is a new member of the mammalian sodium-coupled dicarboxylate/sulfate transporter family. Based on functional characterization and localization, we conclude that SDCT2 mediates high-affinity, sodium-coupled transport of Krebs cycle intermediates in S3 segments of kidney proximal tubule cells, presumably in the basolateral membrane. SDCT2 mediates transport of di- and tricarboxylates with overall the same substrate selectivity as SDCT1 and NaDC-1.

Physiological role of SDCT2 in the kidney. Recent studies indicated that the dicarboxylate transporters rabbit NaDC-1 and rat SDCT1 function on the apical side of the renal proximal tubule epithelia $(14,15,20)$. Microperfusion studies showed that renal uptake of di- and tricarboxylates exceeds the glomerular filtration load $(2,8)$, suggesting that tubular cells must take 

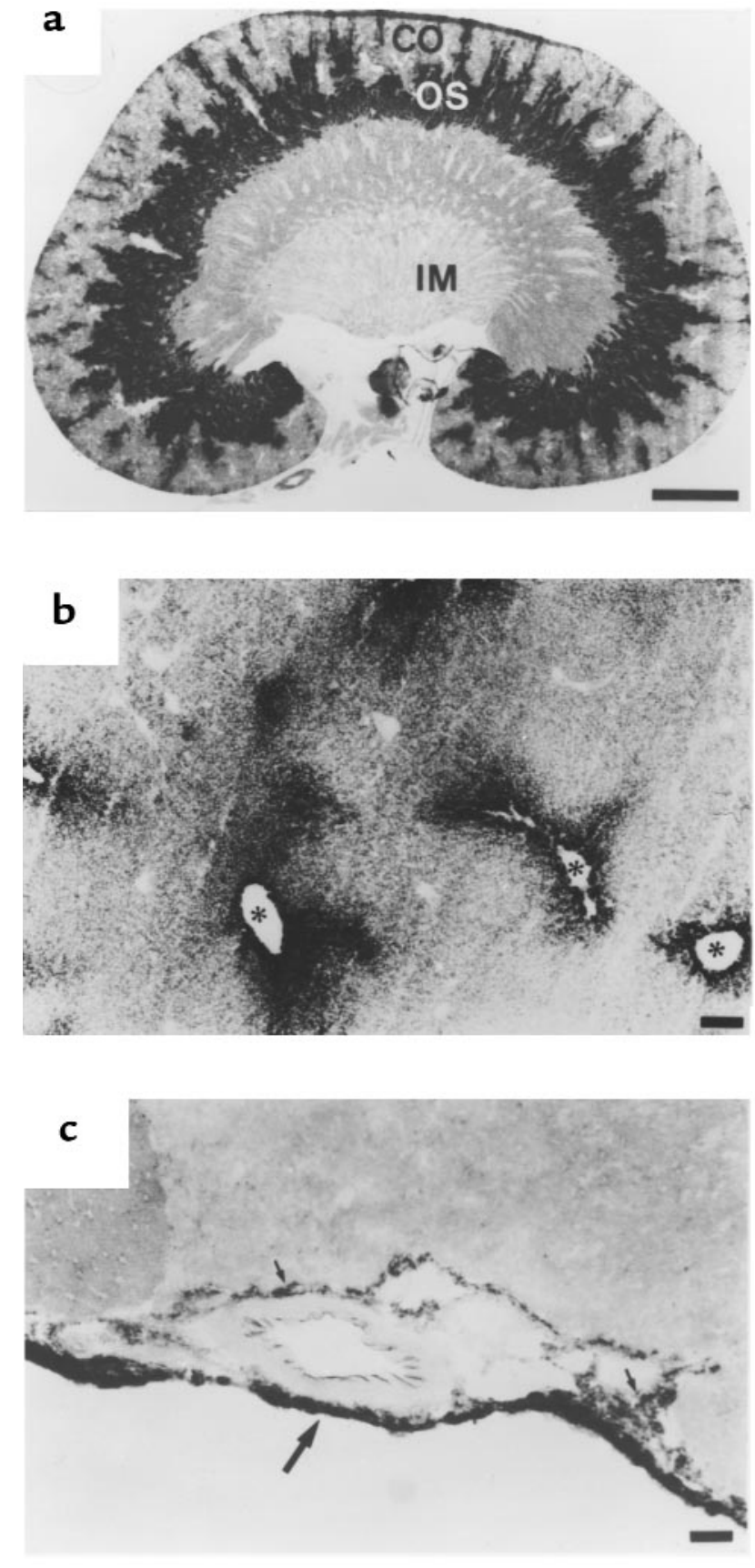

\section{Figure 3}

In situ hybridization of SDCT2 mRNA. Freshly frozen tissue sections $(12 \mu \mathrm{m})$ from rats were hybridized with a digoxigeninlabeled 1.3-kb SDCT2 cRNA probe. Bright-field micrographs of sections hybridized to antisense cRNA probe are shown (a-c). Hybridization of sense cRNA probe did not reveal any signals (data not shown). (a) Cross-section of kidney. A gradient of mRNA levels in S3 segment is apparent; i.e., the signal is more prominent in proximal part of the straight tubules compared with distal parts. CO, cortex; IM, inner medulla; OS, outer stripe of outer medulla. Scale bar: $2 \mathrm{~mm}$. (b) Liver. SDCT2 mRNA is predominantly expressed in hepatocytes surrounding the central vein (asterisks). Scale bar: $200 \mu \mathrm{m}$. (c) Brain. SDCT2 mRNA is expressed by cells of meningeal layers, including dura mater (large arrow), arachnoid, and pia mater (small arrows). Scale bar: $50 \mu \mathrm{m}$. up these substrates from the blood through their basolateral membrane. The relative contribution of luminal reabsorption and peritubular uptake on intracellular accumulation of citrate has been estimated to be $60-70 \%$ and $30-40 \%$, respectively (2). Given that plasma dicarboxylate concentration is on the order of 50 $\mu \mathrm{M}$ or less (6), the high-affinity nature of SDCT2 is ideally suited to enable peritubular uptake of Krebs intermediates on the basolateral side. Our findings that SDCT2 transports succinate with high affinity $\left(K_{\mathrm{m}}^{\text {succ }}=15 \mu \mathrm{M}\right)$, shows preference over citrate, and has a $\mathrm{pH}$ optimum of 7.5-8.5 all agree with the transport characteristics reported for basolateral membrane vesicles $(6,7)$. Furthermore, we found that SDCT2 transports dimethylsuccinate with a 10 -fold higher affinity than SDCT1 (Figure 5b). Perfusion studies with rat proximal tubules demonstrated $(24,25)$ that dimethlysuccinate is transported specifically by the basolateral dicarboxylate transport system, thereby providing a useful test compound to differentiate between apical and basolateral transport. High-affinity transport for both methylsuccinate and dimethylsuccinate by SDCT2 strongly supports its basolateral localization. However, immunocytochemical studies will be required to provide the ultimate proof of this localization. The preferred alkaline $\mathrm{pH}$ of the basolateral transporter may explain the enhancement of dicarboxylate excretion in metabolic alkalosis $(1,2)$.

Our results that SDCT1 and SDCT2 are localized exclusively in S3 proximal tubule segments raises the question of how transport of dicarboxylates is mediated in proximal tubule S1 and S2 segments. A microperfusion study with rabbit proximal tubules (3) indicated that the convoluted tubule has a more than 10-fold higher citrate reabsorptive capacity than the proximal straight tubule. Similarly, micropuncture study with rat tubules (21) demonstrates that approximately $75 \%$ of the filtered $\alpha$-ketoglutarate is reabsorbed in the convoluted proximal tubule and $20 \%$ in the pars recta, supporting the concept that the bulk of citrate transport takes place in S1 and S2 proximal tubule segments. In situ hybridization indicated that the two dicarboxylate transporters, SDCT1 and SDCT2, are both expressed in the straight part of proximal tubule S3 segments $(14,15)$. The exact localization of rabbit and human NaDC- 1 in kidney proximal tubules has not yet been reported. Functional characterization indicated that rabbit $\mathrm{NaDC}-1$ and rat SDCT1 have moderate and high affinity for substrates, respectively. Whether the putative citrate transporter in S1-S2 segments, which displays lowaffinity $\left(K_{\mathrm{m}}=6-7 \mathrm{mM}\right)$ and high-capacity characteristics, corresponds to human NaDC-1 or a different transporter remains to be determined.

Role of SDCT2 in the liver. Considering that the liver and the kidneys are major sites of citrate utilization (2), the role of SDCT2 in hepatocytes is likely to take up Krebs cycle intermediates from the systemic circulation. Previous studies with liver basolateral membrane vesicles (26) suggested the presence of two separate dicarboxylate transport pathways along the sinusoidal membrane. One is a high-affinity dicar- 


\section{Figure 4}

Dicarboxylate transport of SDCT2 expressed in Xenopus oocytes. (a) Radiotracer uptake of succinate and citrate in SDCT2-expressing oocytes. Uptake of $100 \mu \mathrm{M}\left[{ }^{14} \mathrm{C}\right]$ succinate and $1 \mathrm{mM}\left[{ }^{14} \mathrm{C}\right]$ citrate was measured during $10 \mathrm{~min}$ in solution containing sodium or choline. (b) Time course of succinate-evoked currents. Currents were recorded at $\mathrm{pH} 7.5$ and at holding membrane potential $V_{h}=-50$ $\mathrm{mV}$. At 100 or $20 \mathrm{mM} \mathrm{Na}^{+}$, application of 50 $\mu \mathrm{M}$ succinate (filled blocks) and $3 \mathrm{mM} \mathrm{Li}$ (hatched blocks) is indicated. Effects of lithium were analyzed further in Figure $7 \mathrm{~b}$. (c) Concentration dependence of SDCT2-mediated currents. Currents were measured at different concentrations of succinate $(0-200$ $\mu \mathrm{M}, \mathrm{pH}$ 7.5) and at $\mathrm{V}_{\mathrm{h}}=-50 \mathrm{mV}$. (d) Concentration dependence of citrate-evoked currents. Currents were measured at different concentrations of citrate $(0-2.0 \mathrm{mM}, \mathrm{pH} 7.5)$ and at $\mathrm{V}_{\mathrm{h}}=-50 \mathrm{mV}$. a

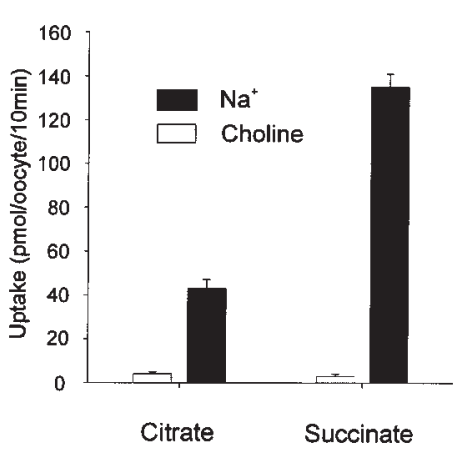

b

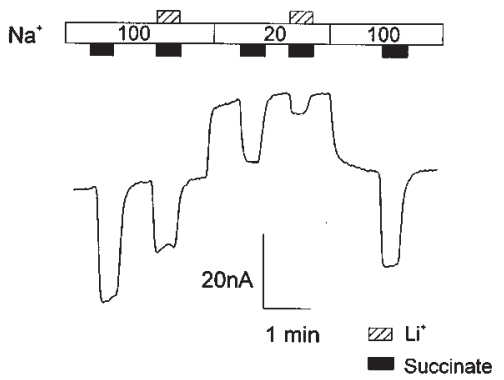

C

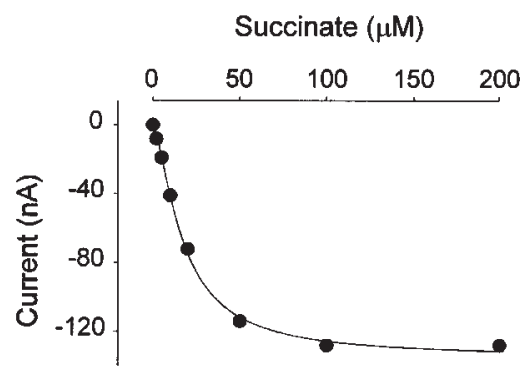

d

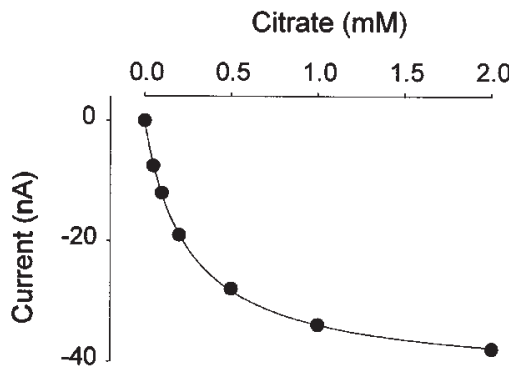

boxylate transporter with a $K_{\mathrm{m}}$ of $\sim 10 \mu \mathrm{M}$, a value that is very close to that reported for kidney basolateral membrane vesicles (6), and the other is a sodium-independent anion-exchange mechanism. Our results indicate that SDCT2 mRNA is predominantly expressed in hepatocytes surrounding the central vein. This perivenous localization is consistent with previous liver perfusion and histoautography studies $(27,28)$. SDCT2 may be associated with glutamine synthesis in the perivenous regions because glutamine synthetase activity is exclusively localized to perivenous hepatocytes and because dicarboxylates are substrates for glutamine synthesis. SDCT2 likely corresponds to the liver sinusoidal dicarboxylate transporter, which plays a role in hepatic glutamine and ammonia metabolism and cooperates with the organic anion/dicarboxylate exchanger OAT2 to facilitate secretion of organic anions from hepatocytes $(29,30)$. a

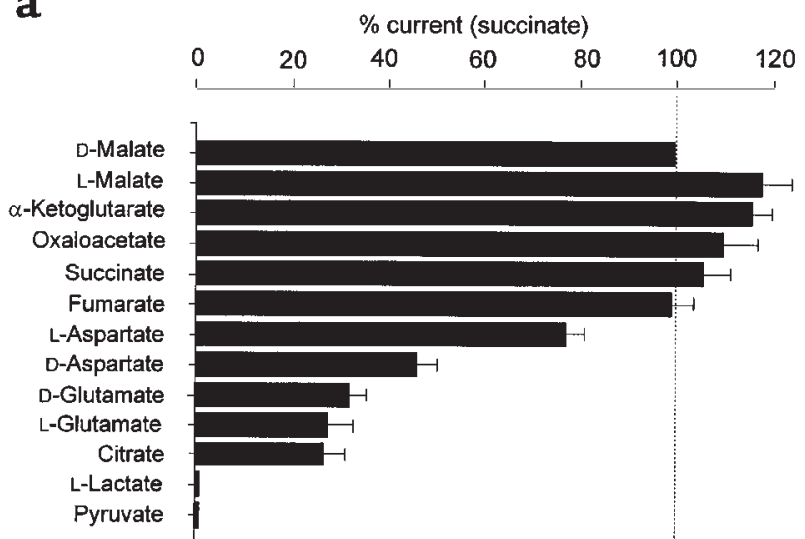

b

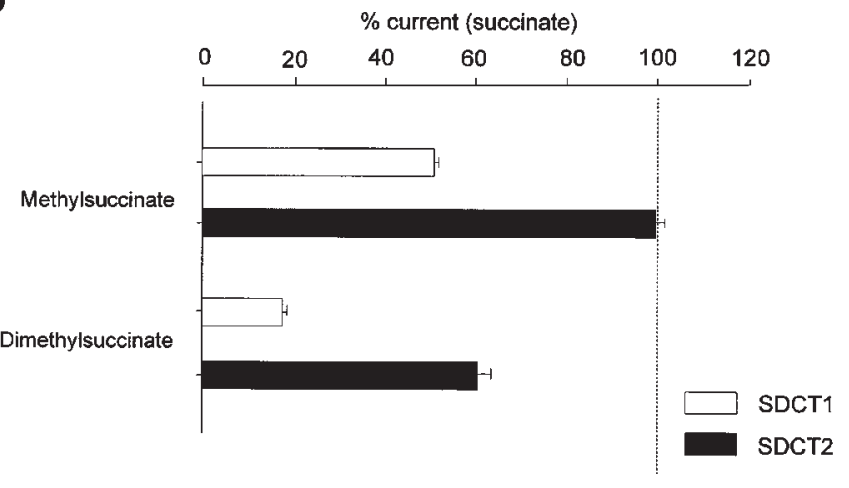

\section{Figure 5}

Substrate specificity of SDCT2. (a) Currents induced by $1 \mathrm{mM}$ substrate are shown as a percentage of those evoked by succinate ( $\mathrm{n}=3-6$ ). Currents generated by different dicarboxylates were in the following order: D-malate, L-malate, $\alpha$-ketoglutarate, oxaloacetate, succinate, fumarate. No measurable currents were detected for monocarboxylates. (b) Comparison of transport selectivity of SDCT1 and SDCT2. Currents evoked by DL-methylsuccinate and 2,3,-dimethylsuccinate $(50 \mu \mathrm{M})$ were measured in the oocytes expressing either SDCT1 (hatched bars) or SDCT2 (filled bars). The currents are indicated as a percentage of the succinate-evoked current $(50 \mu \mathrm{M})$ observed in the same oocyte $(n=3-4)$. 
a

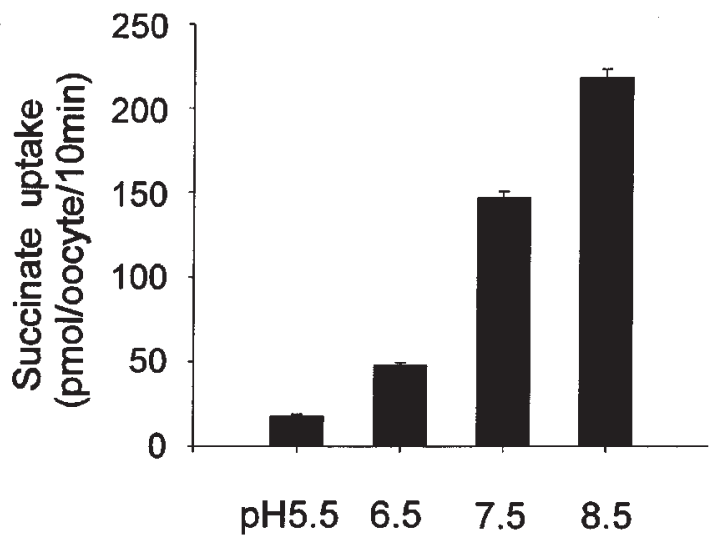

b

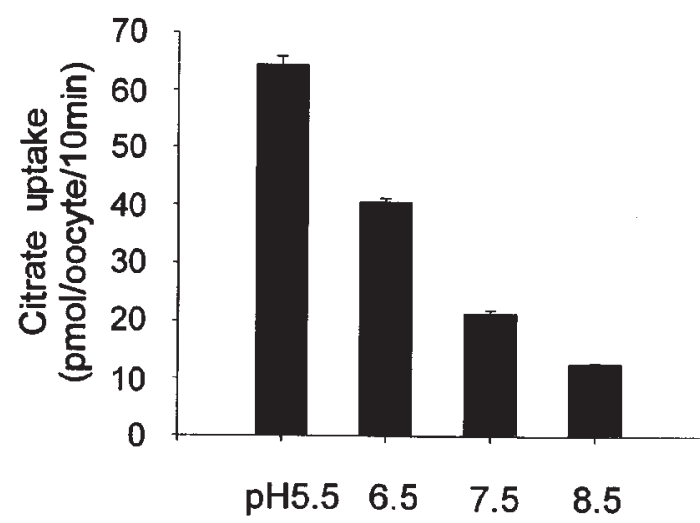

c

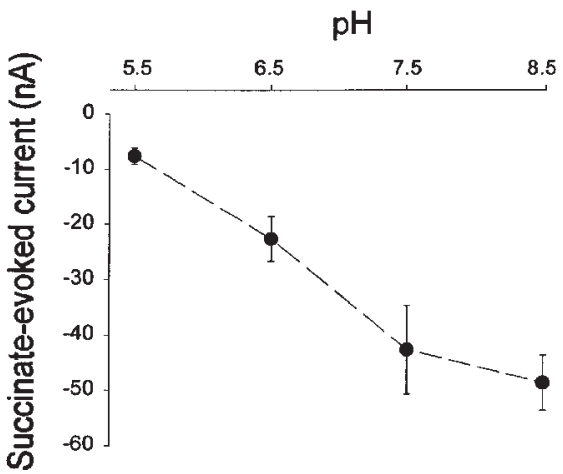

d

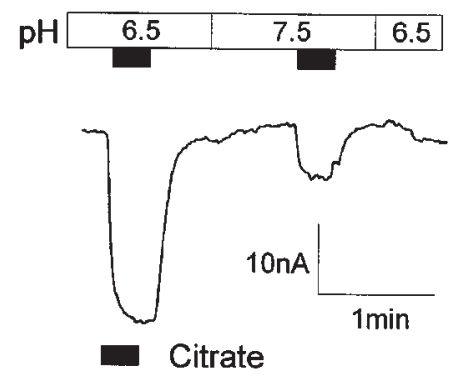

Figure 6

$\mathrm{pH}$ effects on succinate and citrate transport. Proton dependency of uptake for succinate (a) and citrate (b). Uptake of $100 \mu \mathrm{M}\left[{ }^{14} \mathrm{C}\right]$ succinate or $1 \mathrm{mM}\left[{ }^{14} \mathrm{C}\right]$ citrate was measured during $10 \mathrm{~min}$ under indicated $\mathrm{pH}$. (c) $\mathrm{pH}$ dependency of succinate-evoked current. Average currents evoked by succinate $(20 \mu \mathrm{M})$ at four different $\mathrm{pH}$ values from 5.5 to 8.5 were measured $\left(\mathrm{V}_{\mathrm{h}}=-50 \mathrm{mV}, n=3\right)$. (d) $\mathrm{pH}$ dependency of citrate-evoked current. Inward currents generated by citrate $(200 \mu \mathrm{M})$ are demonstrated by superfusing oocytes with solutions at $\mathrm{pH} 6.5$ and $\mathrm{pH} 7.5$, respectively $\left(\mathrm{V}_{\mathrm{h}}\right.$ $=-50 \mathrm{mV}$ ). Citrate addition (filled blocks) is indicated.
SDCT2 and excretion of drugs. SDCT2 likely plays an important role in the excretion of organic anions and small therapeutic drugs, including their gluconate, sulfate, and cysteine conjugates. Their excretion is known to involve release from hepatocytes into the blood and secretion into kidney proximal tubules. In both hepatocytes and renal epithelial cells, dicarboxylate transporters plays an important role because they cooperate with organic anion/dicarboxylate exchangers in liver and kidney (OAT-2 in liver sinusoidal membranes and OAT- 1 in kidney basolateral membranes; refs. 30,31 ) to facilitate excretion of these organic anions and drugs.

Role of SDCT2 in the brain. Our data indicate that SDCT2 mRNA is expressed in cells of the meningeal layers, i.e., pia mater, arachnoid, and dura mater. The expression may reflect the need of these cells to take up dicarboxylates as nourishment. The lack of SDCT2 mRNA in cerebral blood vessels or the choroid plexus suggests that SDCT2 is not involved in the transport of dicarboxylates across the blood-brain barrier. A recent study with perfused rat brain demonstrated that dicarboxylates are transported across the bloodbrain barrier through a transporter that is inhibited by monocarboxylates (32).

Functional comparison of SDCT2 with other dicarboxylate transporters. A striking functional difference between rat SDCT1 and SDCT2 is the proton effect on succinate transport (Figure 6). SDCT2 requires a $\mathrm{pH}$ optimum of 7.5-8.5 to maximize succinate uptake, whereas SDCT1 does not display a $\mathrm{pH}$ dependence for succinate transport (14). The suppression of succinate transport at lower $\mathrm{pH}$ was observed both in uptake studies (Figure 6a) and electrophysiological experiments (Figure 6c). Given that the equilibrium constant $\mathrm{pKa}_{2}$ of succinate is 5.6, the $\mathrm{pH}$ effects suggest that the divalent form of succinate is more predominantly transported by SDCT2 than is the monovalent one. Alternatively, the monovalent form of succinate may behave as a competitive inhibitor to block transport of the divalent species. In contrast, our previous study (14) showed that succinate transport by SDCT 1 is independent of external $\mathrm{pH}$, suggesting that the monovalent form of succinate can be equally transported. This interpretation is consistent with findings of rabbit renal brushborder membrane vesicles (33). Another difference is that SDCT2 has a threefold stronger affinity for citrate than SDCT1 $\left(K_{\mathrm{m}}^{\mathrm{cit}}=220 \pm 10\right.$ vs. $640 \pm 10 \mu \mathrm{M}$, respectively), suggesting that SDCT2 can operate even under lower external citrate concentration. In contrast, other features, including $\mathrm{pH}$ effects on citrate transport, substrate selectivity of di- and tricarboxylates with substrate preference of succinate over citrate, cation specificity, and lithium sensitivity, are very similar for SDCT1 and SDCT2.

There are significant functional differences between SDCT and NaDC isoforms with regard to their substrate affinity, specificity, and cation effect. Compared with rabbit NaDC-1, SDCT1 and SDCT2 show one order of magnitude higher affinity for succinate $\left(K_{\mathrm{m}}{ }^{\text {succ }}=24 \mu \mathrm{M}, 15 \mu \mathrm{M}\right.$, and $400 \mu \mathrm{M}$ for rat SDCT1, rat SDCT2, and rabbit NaDC-1, respectively) and display 
1.5 - to fourfold higher affinity for citrate $\left(K_{\mathrm{m}}^{\mathrm{cit}}=600\right.$ $\mu \mathrm{M}, 200 \mu \mathrm{M}$, and $900 \mu \mathrm{M}$ for rat SDCT1, rat SDCT2, and rabbit $\mathrm{NaDC}-1$, respectively) $(12,14)$. Interestingly, human NaDC-1 has a much lower affinity for citrate than rat SDCT1 and rabbit NaDC- 1 isoforms $\left(K_{\mathrm{m}}^{\mathrm{cit}}\right.$ $7 \mathrm{mM}, 0.6 \mathrm{mM}$, and $0.9 \mathrm{mM}$, respectively) and displays a more pronounced $\mathrm{pH}$ sensitivity than the rabbit isoform (19). The relatively lower affinity of human NaDC-1 may account for higher fractional excretion of citrate (i.e., $10-35 \%$ of glomerular filtration load) compared with those from rat and $\operatorname{dog}(3-7 \%)(1,2)$. Moreover, human NaDC-1 may represent the lowaffinity/high-capacity transporter for which rabbit and rat homologues have not yet been isolated. Differences in cation selectivity between human and rabbit NaDC-1 have also been reported. Transport by rabbit NaDC-1 is more sensitive to lithium than is transport by human NaDC- $1\left(\mathrm{~K}_{i}^{\mathrm{Na}}=2 \mathrm{mM}\right.$ for rabbit and $20 \mathrm{mM}$ for human) (19). In contrast, lithium behaves as an effective coupling cation in NaDC-2 of Xenopus laevis oocytes (17). Our results show that both SDCT1 and SDCT2 display low lithium sensitivity, similar to rabbit NaDC-1 (12). Amphibian cells appear to have a different cation requirement.

Clinical implication of SDCT2. A number of studies highlight the relationship between urinary citrate excretion and calcium nephrolithiasis $(2,34)$. Citrate is normally the most abundant urinary organic acids and functions as an endogenous inhibitor for renal stone formation. Maintenance of urine citrate levels is essential to prevent the precipitation of calcium salts, e.g., calcium oxalate (2). The incidence of low urinary citrate has been reported to be $20-60 \%$ in patients with calcium nephrolithiasis (2). Oral citrate administration has been shown to increase urinary citrate and to be effective in the treatment of nephrolithiasis (35). Elucidation of the molecular mechanisms of citrate excretion is essential to designing therapeutic approaches for the treatment of this common disorder. Because the urinary citrate concentration is determined by reabsorption of citrate from kidney proximal tubules (2), transport on the luminal side is thought to be important in regulating the urinary citrate content. However, changes in dicarboxylate uptake on the basolateral side may influence cellular metabolism inside the tubular cells and intracellular $\mathrm{pH}$ and hence affect the transport on the luminal side $(1,2)$. Numerous studies indicated that systemic acid-base balance is the most important regulatory factor for urinary citrate excretion (36). In fact, in humans, citrate excretion is enhanced two- to fivefold (up to $60 \%$ of filtered citrate may appear in the urine) in alkalosis. Moreover, several other metabolic factors, including electrolyte and nutrition imbalance (e.g., chronic hypokalemia [37] and fasting [38]), also influence citrate excretion. Further studies on the regulation of both SDCT1 and SDCT2 under pathological conditions will help toward understanding the pathogenesis of hypocitraturia and nephrolithiasis.

Note added in proof. Kekuda et al. recently described a transporter from rat placenta (NaDC3) with characteristics similar to SDCT2 (1999, J. Biol. Chem. 274:3422-3429). a

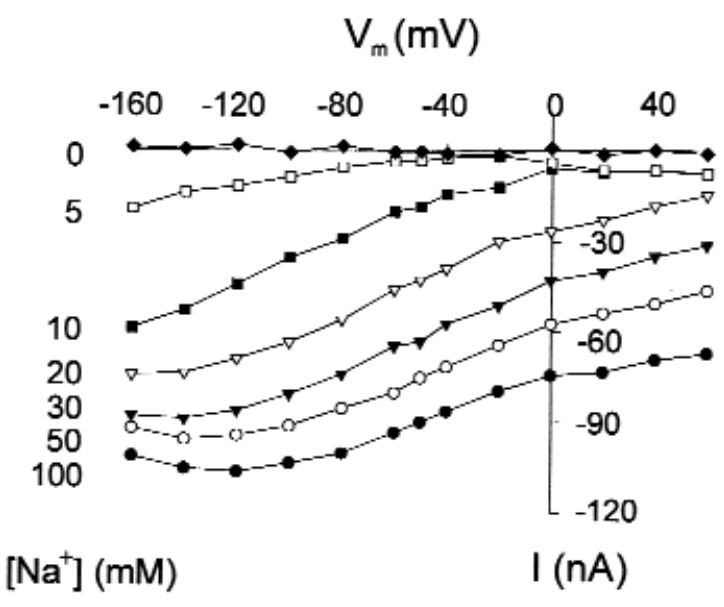

b

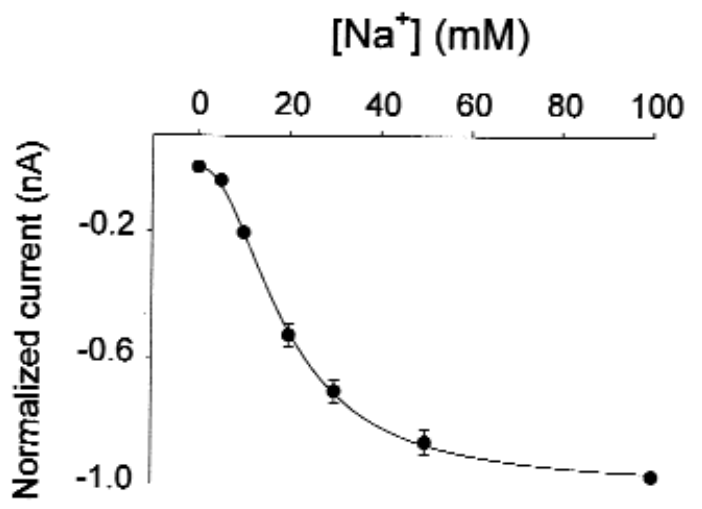

C

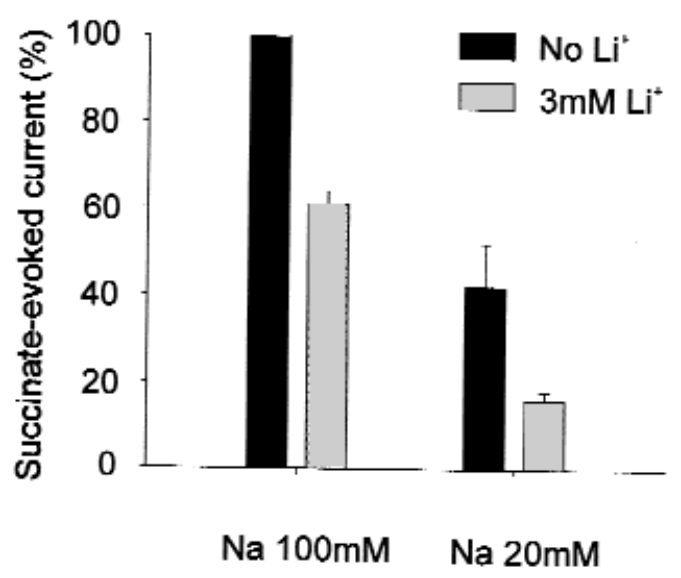

Figure 7

Cationic effects on succinate-evoked currents. (a) Current-voltage relationship under various sodium concentrations. Under different sodium concentrations $(0-100 \mathrm{mM})$, steady-state current and voltage relation between -160 to $+60 \mathrm{mV}$ were obtained by subtracting currents in the presence and absence of $100 \mu \mathrm{M}$ succinate. (b) Sigmoidal relationship of currents versus sodium concentration. At $V_{h}=-50 \mathrm{mV}$, currents evoked by $100 \mu \mathrm{M}$ succinate at different sodium concentrations were normalized by those at $100 \mathrm{mM} \mathrm{NaCl}$ medium. The curve was fitted by the Hill equation. (c) Effects of lithium on SDCT2 currents. Succinate-evoked currents (at $50 \mu \mathrm{M}$ ) in the presence or absence of lithium are shown as a percentage of those at $100 \mathrm{mM} \mathrm{NaCl}$ medium without $\mathrm{Li}^{+}$. In absence of $\mathrm{Li}^{+}$, average currents at $20 \mathrm{mM} \mathrm{Na}^{+}$are $42 \pm 10 \%$ of those at $100 \mathrm{mM} \mathrm{Na}^{+}$. 


\section{Acknowledgments}

We are grateful to Ji-Bin Peng and Tong Zhu (Brigham and Women's Hospital ) for their assistance in oocyte expression studies, and Peying Fong (Yale University) for providing a pTLN2 vector. This work was supported by National Institutes of Health grant DK43171 (to M.A. Hediger). H. Tsukaguchi was supported by a fellowship grant from the National Kidney Foundation. X.-Z. Chen is the recipient of the Long-Term Fellowship from the International Human Frontier Science Program. U.V. Berger is supported by the NIH Training Program in Academic Nephrology.

1. Murer, H., Manganel, M., and Roch-Ramel, F. 1992. Tubular transport of monocarboxylates, Krebs cycle intermediates, and inorganic sulfate. In Handbook of physiology: renal physiology. E.E. Windhager, editor. American Physiological Society. Bethesda, MD. 2165-2188.

2. Hamm, L.L. 1990. Renal handling of citrate. Kidney Int. 38:728-735.

3. Brennan, S., Hering-Smith, K., and Hamm, L.L. 1988. Effect of pH on citrate reabsorption in the proximal convoluted tubule. Am. J. Physiol. 255:F301-F306

4. Wright, E.M. 1985. Transport of carboxylic acids by renal membrane vesicles. Annu. Rev. Physiol. 47:127-141.

5. Wright, S.H., Kippen I., and Wright, E.M. 1982. Effect of pH on the transport of Krebs cycle intermediates in renal brush border membranes. Biochim. Biophys. Acta. 684:287-290.

6. Wright, S.H., and Wunz, T.M. 1987. Succinate and citrate transport in renal basolateral and brush-border membranes. Am. J. Physiol. 253:F432-F439.

7. Burckhardt, G. 1984. Sodium-dependent dicarboxylate transport in rat renal basolateral membrane vesicles. Pflugers Arch. 401:254-261.

8. Simpson, D.P. 1983. Citrate excretion: a window on renal metabolism. Am. J. Physiol. 244:F223-F234.

9. Moller, J.V., and Sheikh, M.I. 1983. Renal organic anion transport system: pharmacological, physiological, and biochemical aspects. Pharmacol. Rev. 34:315-358.

10. Pritchard, J.B., and Miller, D.S. 1993. Mechanisms mediating renal secretion of organic anions and cations. Physiol. Rev. 73:765-796.

11. Pak, C.Y.C. 1987. Citrate and renal calculi. Miner. Electrolyte Metab. 13:257-266.

12. Pajor, A.M. 1995. Sequence and functional characterization of a renal sodium/dicarboxylate cotransporter. J. Biol. Chem. 270:5779-5785.

13. Pajor, A.M. 1996. Molecular cloning and functional expression of a sodium-dicarboxylate cotransporter from human kidney. Am. J. Physiol. 270:F642-F648

14. Chen, X.-Z., Shayakul, C., Berger, U.V., Tian, W., and Hediger, M.A. 1998. Characterization of a rat $\mathrm{Na}^{+} /$dicarboxylate cotransporter. J. Biol. Chem. 273:20972-20981.

15. Sekine, T., Cha, et al. 1998. Cloning, functional characterization, and localization of a rat renal $\mathrm{Na}^{+}$-dicarboxylate transporter. Am. J. Physiol. 275:F298-F305.

16. Khatri, I.A., Kovacs, S.V., and Forstner, J.F. 1996. Cloning of the cDNA for a rat intestinal $\mathrm{Na}^{+}$/dicarboxylate cotransporter reveals partial sequence homology with a rat intestinal mucin. Biochim. Biophys. Acta. 1309:58-62.

17. Bai, L. and Pajor, A.M. 1997. Expression cloning of NaDC-2, an intestinal $\mathrm{Na}^{+}$or $\mathrm{Li}^{+}$-dependent dicarboxylate transporter. Am. J. Physiol. 273:G267-G274.
18. Markovich, D., Forgo, J., Stange, G., Biber, J., and Murer, H. 1993. Expression cloning of rat renal Na+/ $\mathrm{SO}_{4}{ }^{2-}$ cotransport. Proc. Natl. Acad. Sci. USA. 90:8073-8077.

19. Pajor, A.M., and Sun, N. 1996. Functional differences between rabbit and human $\mathrm{Na}+$-dicarboxylate cotransporters, NaDC-1 and hNaDC-1. Am. J. Physiol. 271:F1093-F1099.

20. Pajor, A.M., and Sun, N. 1996. Characterization of the rabbit renal $\mathrm{Na}^{(+)}$dicarboxylate cotransporter using antifusion protein antibodies. Am.J. Physiol. 271:C1808-C1816.

21. Ferrier, B., Martin, M., and Baverel, G. 1985. Reabsorption and secretion of alpha-ketoglutarate along the rat nephron: a micropuncture study. Am. J. Physiol. 248:F404-F412.

22. Romero, M.F., Fong, P., Berger, U.V., Hediger, M.A., and Boron, W.F. 1998. Cloning and functional expression of $\mathrm{rNBC}$, an electrogenic $\mathrm{Na}{ }^{(+)}$$\mathrm{HCO}_{3}$-cotransporter from rat kidney. Am. J. Physiol. 274:F425-F432.

23. Berger, U.V., Tsukaguchi, H., and Hediger, M.A. 1998. Distribution of mRNA for the facilitated urea transporter UT3 in the rat nervous system. Anat. Embryol. (Berl.). 197:405-414.

24. Ullrich K.J., Fasold H., Rumrich G., and Kloss S. 1984. Secretion and contraluminal uptake of dicarboxylic acids in the proximal convolution of rat kidney. Pflugers Arch. 400:241-249.

25. Sheridan E., Rumrich G., and Ullrich K.J. 1983. Reabsorption of dicarboxylic acids from the proximal convolution of rat kidney. Pflugers Arch. 399:18-28.

26. Zimmerli, B., O’Neill, B., and Meier, P.J. 1992. Identification of sodiumdependent and sodium-independent dicarboxylate transporter systems in rat liver basolateral membrane vesicles. Pflugers Arch. 421:329-335.

27. Moseley, R.H., Jarose, S., and Permoad, P. 1992. Hepatic $\mathrm{Na}^{(+)}$-dicarboxylate cotransport: identification, characterization, and acinar localization. Am. J. Physiol. 263:G871-G879.

28. Stoll, B., and Haussinger, D. 1991. Hepatocyte heterogeneity in uptake and metabolism of malate and related dicarboxylates in perfused rat liver. Eur. J. Biochem. 195:121-129.

29. Boelsterli, U.A., Zimmerli, B., and Meier, P.J. 1995. Identification and characterization of a basolateral dicarboxylate/cholate antiport system in rat hepatocytes. Am. J. Physiol. 268:G797-G805.

30. Sekine, T., Watanabe, N., Hosoyamada, M., Kanai,Y., and Endou, H. 1997. Expression cloning and characterization of a novel multispecific organic anion transporter. J. Biol. Chem. 272:18526-18529.

31. Sekine, T., et al .1998. Identification of multispecific organic anion transporter 2 expressed predominantly in the liver. FEBS Lett. 429:179-182.

32. Ackley, D.C., and Yokel, R.A. 1997 Aluminum citrate is transported from brain into blood via the monocarboxylic acid transporter located at the blood brain barrier. Toxicology. 120:89-97.

33. Barac-Nieto, M. 1984. Effects of $\mathrm{pH}$, calcium, and succinate on sodium citrate cotransport in renal microvilli. Am. J. Physiol. 247:F282-F290.

34. Pak, C.Y.C. 1991. Etiology and treatment of urolithiasis. Am. J. Kidney Dis. 18:624-637.

35. Sakhaee, K., Nicar, M., Hill, K., and Pak, C.Y.C. 1983. Contrasting effects of potassium citrate and sodium citrate therapies on urinary chemistries and crystallization of stone-forming salts. Kidney Int. 24:348-352.

36. Jenkins, A.D., Dousa, T.P., and Smith, L.H. 1985. Transport of citrate across renal brush border membrane: effects of dietary acid and alkali loading. Am. J. Physiol. 249:F590-F595.

37. Levi, M., McDonald, L.A., Preisig, P.A., and Alpern, R.J. 1991. Chronic K depletion stimulates rat renal brush-border membrane $\mathrm{Na}^{+}$-citrate cotransporter. Am. J. Physiol. 261:F767-F773.

38. Windus, D.W., Cohn, D.E., and Heifets, M. 1986. Effects of fasting on citrate transport by the brush-border membrane of rat kidney. Am. J. Physiol. 251:F678-F682. 